This journal is the official publication of Bangladesh Society of Physiologists (BSP)

Web URL: www.banglajol.info/index.php/JBSP

Abstracted/indexed in Index Copernicus, Director of Open Access Journal, HINARI Index Medicus for South East Asia Region, Google Scholar, 12OR, infobse index, Open J gate, Cite factor, Scientific indexing services

pISSN-1983-1213; e-ISSN-2219-7508

\title{
Article
}

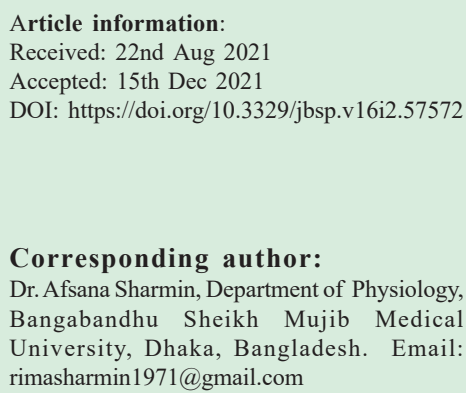

This article is open access licensed under CC BY NC SA which allows readers copy, distribute, display, and perform the work and make derivative works based on it only for noncommercial purposes.

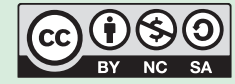

\section{Relationship of heart rate variability with serum zinc and magnesium in female rheumatoid arthritis patients}

\author{
Afsana Sharmin ${ }^{1}$, Meftahul Jannat ${ }^{1}$, Shamima Sultana ${ }^{1}$, \\ Sultana Ferdousi ${ }^{1}$ \\ 1. Department of Physiology, Bangabandhu Sheikh Mujib Medical \\ University, Dhaka, Bangladesh
}

\section{Abstract}

Background: Rheumatoid arthritis (RA) is a chronic inflammatory autoimmune disease affecting multiple small symmetrical joints with extra-articular involvement. Altered blood mineral status is associated with the immune-inflammatory rheumatoid process. Reduced heart rate variability (HRV) is a predictor of sudden cardiac death in RA patients. So, the role of minerals for altered HRV needs investigation in RA. Objectives: To assess the relationship between $\mathrm{HRV}$ and serum zinc ( $\mathrm{Zn}$ ), magnesium and $(\mathrm{Mg})$ levels in RA patients. Methods: This cross sectional study enrolled 60 female participants of 30-50 years of age. Among them 30 female RA patients were included in the study group and 30 age matched apparently healthy women constituted control group. Serum $\mathrm{Zn}, \mathrm{Mg}$ levels were estimated by autoanalyzer and frequency domain parameters of HRV were recorded by a data acquisition device, Powerlab 8/35, AD Instruments, Australia followed by analysis with software, Lab chart. Statistical analyses were done by independent sample ' $t$ ' test and Pearson's correlation coefficient test. Results: In this study, among frequency domain parameters of $\mathrm{HRV}$, total power (TP), low frequency power(LF), high frequency power(HF), HF normalized unit(HF nu) were significantly lower $(\mathrm{p}<0.05)$ and LF normalized unit (LF nu), LF/HF ratio were significantly higher $(p<0.05)$ in RA patients. In addition, significantly $(p<0.05)$ lower levels of serum $\mathrm{Zn}$ and $\mathrm{Mg}$ were found in RA patients as compared to controls. But on correlation analysis, the HF nu showed significant positive correlation and LF nu and LF/HF 
ratio demonstrated significant negative correlation $(\mathrm{p}<0.05)$ with serum Mg only. Conclusion: Results of the present study revealed that low levels of serum $\mathrm{Mg}$ was correlated with reduced HRV in patients with RA. Moreover, low serum Mg was related to parasympathetic hypo and sympathetic hyperactivity as well as altered sympathovagal balance in RA.

Keywords: Rheumatoid arthritis, Heart rate variability, Zinc, Magnesium.

Introduction

$\mathbf{R}$ heumatoid arthritis (RA) is the commonest joint disease with considerable disability, compromised quality of life and premature mortality prevalent in the industrialized as well as in developing world. ${ }^{1}$ The most prominent feature of RA is symmetrical polyarthritis involving small synovial joints of hand, wrist, feet, ankle, knee. ${ }^{2-3}$

This disabling disease has worldwide distribution, hence is a global public health concern. ${ }^{4-5}$ Almost all ethnic groups and races are affected by RA. ${ }^{6}$ Overall pooled prevalence of RA in Bangladesh is about $0.7 \%$. This progressive disabling disease impacts heavily upon treatment expenses and productivity of the affected patients. Thus, RA imposes a great economic burden on health outcome. ${ }^{2,7-8}$ Despite high incidence of RA globally as well as locally it is often a neglected medical issue in developing country like Bangladesh.

Progressive disabilities with non articular complications deteriorate patient's quality of life seriously. Among many risk factors, minerals and trace elements disorders have been recognized as risk factors of RA. ${ }^{3,5,9}$ Previous studies reported chronic inflammation induced marked systemic alteration in blood mineral levels causing pathogenesis in RA patients. ${ }^{1-3,5,9-13}$

In addition to joints, RA adversely affects all the organ and system of the body and cardiovascular morbidity and mortality is well marked in RA patients. ${ }^{14-15}$ As because, cardiovascular involvement is silent, more than $40 \%$ of the premature deaths occur in RA due to cardiovascular diseases $(\mathrm{CVD})^{16}$

Analysis of HRV has been emerged as most reliable and non-invasive method for assessment of cardiac autonomic activity and reduced HRV is a marker of autonomic imbalance, which is a strong predictor of sudden cardiac death. ${ }^{17} \mathrm{HRV}$ analysis by frequency domain parameters, is most widely used non invasive tool which distinguishes the original HRV signal into specific frequency band and reflects the amplitude of the signals of heart rate fluctuation at different frequency ranges. This difference in frequency ranges can differentiate the sympathetic and parasympathetic component of autonomic nervous system. Therefore frequency domain analysis represents more precise assessment of cardiac autonomic activity. ${ }^{18}$ Previous studies reported that RA was associated with significantly reduced HRV. ${ }^{16,19-20}$ Among the blood minerals, low serum $\mathrm{Mg}$ and $\mathrm{Zn}$ has been found associated with RA which increases risk of CVD in RA. ${ }^{8,11,21-22}$ Previous studies demonstrated that serum Mg deficiency was found to be associated with autonomic dysfunction. Studies on healthy adult Korean women and hypomagnesemia patients showed that serum $\mathrm{Mg}$ was significantly positively correlated with some HRV indices. ${ }^{23-24}$ whereas no association was observed between serum $\mathrm{Zn}$ level and cardiovascular autonomic function in pregnant women with gestational

Volume 16 No. 2 December 2021: 111-117 
hypertension. ${ }^{25}$ But no published data was found regarding the relationship of serum $\mathrm{Zn}$ and $\mathrm{Mg}$ level with HRV in patients with RA. Therefore, the present study has been designed to assess the relationship between reduced $\mathrm{HRV}$ and serum levels of $\mathrm{Zn}, \mathrm{Mg}$ in patients with RA.

\section{Methods}

Setting and study participants

This cross sectional study was carried out in the Department of Physiology of Bangabandhu Sheikh Mujib Medical University (BSMMU), Dhaka from March, to February, 2021.Thirty female RA patients aged 30-50 years were enrolled by purposive sampling from the Outpatient Department of Rheumatology, BSMMU, Dhaka according to selection criteria. Thirty age and BMI match apparently healthy female subjects were also studied as control. Protocol was approved by Institutional Review Board (IRB) of BSMMU.

\section{Selection criteria}

The patients who had history or currently suffering from- cardiovascular disorders, respiratory disorders, renal insufficiency, liver disease, arthritis other than RA, neurological disorders, thyroid disorders, psychiatric disorders, malignancy, pregnancy and also the patients under medications for cardiac disease or respiratory disease or for other reasons which might interfere with autonomic nervous system balance or serum mineral status, current smokers were excluded from this study.

\section{Data collection procedure}

For this study, informed written consent was taken from each participant after briefing the aim, benefit and procedure of the study.

Then detailed history was taken and thorough physical examination was done and information was documented in a preformed standard data sheet. Then under aseptic precaution, venous blood was collected for estimation of some biochemical parameters. Fasting blood glucose and serum creatinine as well as serum levels of $\mathrm{Zn}, \mathrm{Mg}$ were estimated by standard laboratory technique in the Department of Biochemistry and Molecular Biology, BSMMU, Dhaka. Finally selected subjects were then instructed about proper preparation before recording of HRV data. The subjects were instructed to take their meal by 9:00 pm and to have a sound sleep at the previous night, without any physical or mental stress and not to take any sedatives, hypnotic medication. Then on the test day, patients were requested to take light breakfast in the morning without tea or coffee and then attend to the autonomic nerve function laboratory in the Department of Physiology, BSMMU between 89 a.m. After that, the subjects were given complete bed rest in supine position for 10-15 minutes in a temperature and sound controlled laboratory environment. Then HRV was recorded by a digital data acquisition device(Powerlab 8/35, AD instruments, Australia) to assess cardiac autonomic nerve function. During the procedure, any talking, eating or drinking as well as performing physical or mental activity even sleep were prohibited.

\section{Statistical analysis}

Data were expressed as mean $\pm \mathrm{SD}$. For statistical test, independent sample ' $\mathrm{t}$ ' test and Pearson's correlation coefficient test were applied by using SPSS version 16 . Value of probability $\mathrm{P}<0.05$ was considered as level of statistical significance.

\section{Results}

General characteristics of the subjects were presented in Table I. In this study, age and BMI were comparable between groups but resting pulse rate, systolic and diastolic blood pressure were significantly higher $(\mathrm{p}<0.01)$ in RA patients compared to controls. In this study, significantly $(p<0.01)$ lower values of TP, LF power, HF power, HF nu and higher value of LF nu, LF/HF ratio were observed in RA patients compared to controls (Table II). In addition, significantly $(\mathrm{p}<0.05)$ lower serum $\mathrm{Zn}$ and $\mathrm{Mg}$ levels were found in RA (Table II). On correlation analysis, only serum $\mathrm{Mg}$ showed significant $(\mathrm{p}<0.05)$ positive correlation with $\mathrm{HF}$ power and significant $(p<0.05)$ negative correlation with LF nu, LF/HF ratio in RA patients (Figure 1, 2, 3). 
Table II: Frequency domain measures of HRV, serum $\mathrm{Zn}$ and $\mathrm{Mg}$ levels in two groups $(\mathrm{N}=60)$

\begin{tabular}{|c|c|c|c|}
\hline Variables & $\mathrm{RA}(\mathrm{n}=30)$ & Control $(n=30)$ & $\mathrm{p}$ value \\
\hline $\begin{array}{l}\mathrm{TP} \\
\left(\mathrm{ms}^{2}\right)\end{array}$ & $\begin{array}{c}649.19 \pm 736.92 \\
(15.7-3246)\end{array}$ & $\begin{array}{c}1736.66 \pm 1239.94 \\
(176.23-4695)\end{array}$ & $0.000^{* * *}$ \\
\hline LF power & $300.36 \pm 323.11$ & $617.08 \pm 486.26$ & $0.005^{* *}$ \\
\hline$\left(\mathrm{ms}^{2}\right)$ & $(9.24-1541)$ & $(57.7-1941)$ & \\
\hline HF power & $144.53 \pm 227.71$ & $705.21 \pm 671.81$ & $0.000^{* * *}$ \\
\hline$\left(\mathrm{ms}^{2}\right)$ & $(2.05-997.8)$ & $(41.14-3234)$ & \\
\hline LF norm & $66.73 \pm 12.89$ & $45.88 \pm 15.32$ & $0.000^{* * *}$ \\
\hline (n.u.) & $(26.21-83.12)$ & $(17.29-64.7)$ & \\
\hline HF norm & $32.59 \pm 12.33$ & $53.01 \pm 14.50$ & $0.000^{* * *}$ \\
\hline (n.u.) & $(16.57-73.22)$ & (33.26-81.44) & \\
\hline \multirow[t]{2}{*}{$\mathrm{LF} / \mathrm{HF}$ ratio } & $2.42 \pm 1.12$ & $0.99 \pm 0.52$ & $0.000^{* * *}$ \\
\hline & $(0.36-5.02)$ & $(0.22-1.95)$ & \\
\hline \multirow[t]{2}{*}{$\mathrm{Zn}(\mu \mathrm{gm} / \mathrm{dL})$} & $87.9 \pm 22.85$ & $102.17 \pm 27.48$ & $0.033^{*}$ \\
\hline & $(50-139)$ & $(57-146)$ & \\
\hline \multirow[t]{2}{*}{$\mathrm{Mg}(\mathrm{mg} / \mathrm{dL})$} & $1.91 \pm 0.21$ & $2.05 \pm 0.26$ & $0.024^{*}$ \\
\hline & $(1.5-2.2)$ & $(1.5-2.6)$ & \\
\hline
\end{tabular}

Data were expressed as Mean \pm SD. Values in parentheses indicate ranges; Statistical analysis was done by Independent sample ' $t$ ' test; RA-Rheumatoid arthritis; TP- total power; LF power- low frequency power; HF power- high frequency power; LF norm- low frequency power in normalized unit; HF norm- high frequency power in normalized unit; LH/HF ratio- low frequency and high frequency power ratio; $\mathrm{n}=$ number of subjects in each group; ${ }^{*} \mathrm{p}<0.05^{* *} \mathrm{p}<0.01 ;{ }^{* * *} \mathrm{p}<0.001 ;$

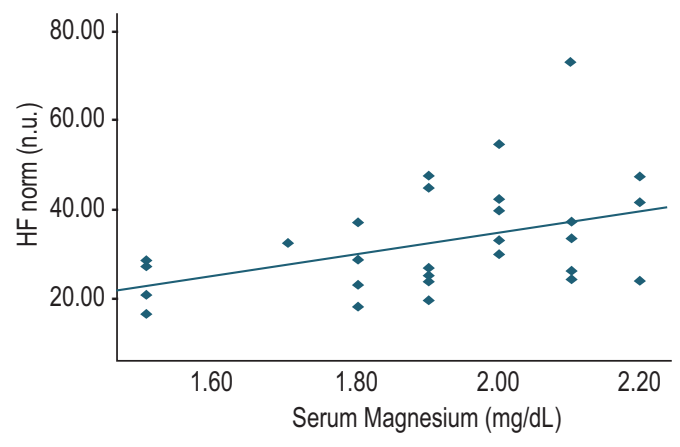

Figure 1: Correlation of HF nu $\left(\mathrm{ms}^{2}\right)$ with serum $\mathrm{Mg}$ level (mg/dL) in group RA. HF nu was positively correlated with serum $\mathrm{Mg}$. RA = Rheumatoid arthritis, HF norm = High frequency power in normalized unit.

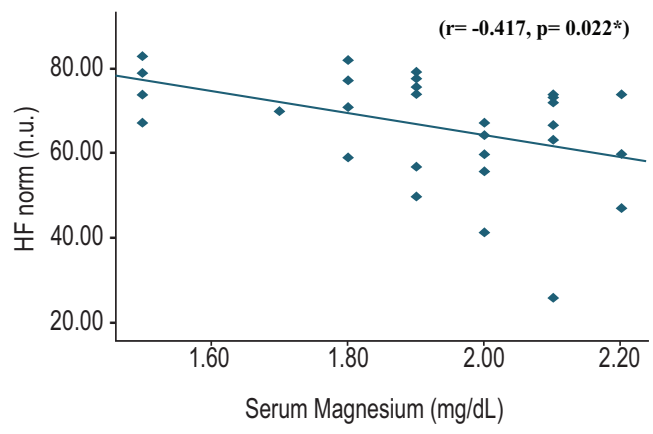

Figure 2: Correlation of LF nu $\left(\mathrm{ms}^{2}\right)$ with serum $\mathrm{Mg}$ level (mg/dL) in group RA. LF nu $\left(\mathrm{ms}^{2}\right)$ was neatively correlated with serum $\mathrm{Mg}$ level. $\mathrm{RA}=$ Rheumatoid arthritis, HF norm = High frequency power in normalized unit.

Volume 16 No. 2 December 2021: 111-117 


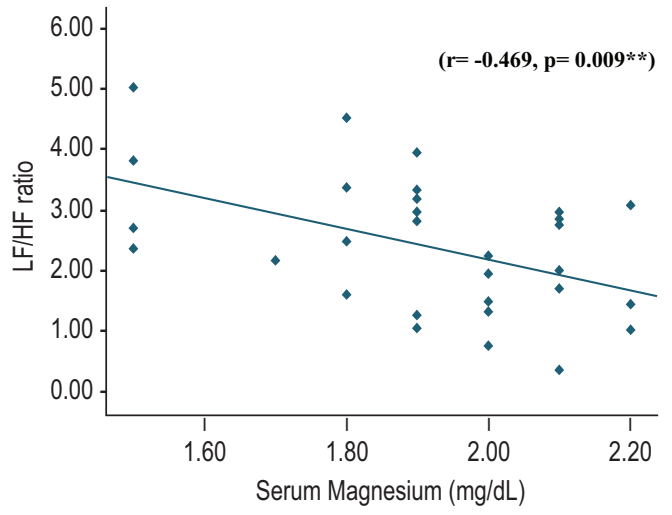

Figure 3: Correlation of $\mathrm{LF} / \mathrm{HF}$ ratio with serum $\mathrm{Mg}$ level (mg/dL) in group RA. LF/ HF ratio was negatively correlated with serum $\mathrm{Mg}$ level. $\mathrm{RA}=$ Rheumatoid arthritis, LH/HF ratio $=$ Low frequency and high frequency power ratio.

\section{Discussion}

The present study investigated the relationship of HRV with serum $\mathrm{Zn}, \mathrm{Mg}$ level in 30-50 years of age female RA patients. Almost similar age range but both genders RA patients were enrolled in a previous study. ${ }^{5}$ This particular age range was chosen for this study because RA is most frequently diagnosed around this age as it is highly prevalent in between $35-50$ years. ${ }^{1}$ However, BMI was slightly lower in RA patients compared to controls but that difference was statistically non-significant. Therefore, two important confounding factors- age and BMI were adjusted in both groups..$^{1,2-3}$ In this study, higher resting pulse rate, SBP and DBP in RA patients agree to others and suggest slight derangement of cardiovascular autonomic regulation. ${ }^{20,26-27}$ Among the results of frequency domain HRV variables, lower values of TP, LF power, HF power, HF nu suggest hypo parasympathetic tone and higher value of LF nu, LF/HF ratio suggestive of hyper sympathetic tonic activity and shifting of sympathovagal balance towards more sympathetic dominance in the present series of RA were consistent with the findings of other researchers. ${ }^{20,27-28}$ This demonstrates impaired cardiac autonomic regulation with sympathetic dominance and decreased parasympathetic modulation is associated with RA. The current study also revealed association lower serum $\mathrm{Zn}$ and $\mathrm{Mg}$ with RA. This result is also supported by some previous studies. ${ }^{1-3,8,11,21-22}$ On further analysis, significant positive correlation of $\mathrm{HF}$ nu and negative correlation of LF nu and LF/HF ratio with serum Mg suggest that decreasing level of serum $\mathrm{Mg}$ is related to reduced parasympathetic activity and increased cardiac sympathetic, altered sympathovagal balance to sympathetic dominance in Rheumatoid arthritis. This finding is novel and it demonstrated the contribution of $\mathrm{Mg}$ deficiency to cardiac autonomic dysregulation in RA. Scientific literature suggested that $\mathrm{Mg}$ deficiency promotes oxidative stress, inflammatory response which could contribute to the pathogenesis of several cardiovascular diseases such as atherosclerosis, hypertension, arrhythmia and sudden cardiac death. It was reported that a high incidence of sudden death in Mg-deficient rats was related to arrhythmias, coronary vasospasm and ANS dysfunction. ${ }^{24}$ The role of low $\mathrm{Mg}$ for cardiac autonomic derangement in the present study can be explained by the chronic inflammation and immune modulation that are chiefly involved in RA pathogenesis. Thus, low levels of serum magnesium may be considered as potent risk factors for CVD events in patients with RA.

\section{Conclusion}

The results of the present study revealed that low levels of serum $\mathrm{Mg}$ was related to reduced HRV in patients with RA. Moreover, low serum $\mathrm{Mg}$ was related to parasympathetic hypo and sympathetic hyperactivity as well as altered sympathovagal balance in this particular patient cohort. Association of serum Mg status alteration with reduced HRV is an important predictor of increased risk of sudden cardiac death in patients with RA.

Conflict of interest: Declared none 


\section{References}

1. Das DC, Jahan I, Uddin MG, Hossain MM, Chowdhury MAZ, Ferdous Z, Rahman MM, Kabir AKMH, Deb SR, Siddique MAB, Das A.Serum CRP, MDA, vitamin $\mathrm{C}$ and trace elements in Bangladeshi patients with rheumatoid arthritis. Biol Trace Elem Res 2021; 199:76-84. doi:10.1007/s12011-02002142-7.

2. Xin L, Yang X, Cai G, Fan D, Xia Q, Liu L, Hu Y, Ding N, Xu S, Wang L, Li X, Zou Y, Pan F. Serum levels of copper and zinc in patients with rheumatoid arthritis: a meta-analysis. Biol Trace Elem Res 2015; 168: 1-10. doi: 10.1007/s12011015-0325-4.

3. Ma Y, Zhang X, Fan D, Xia Q, Wang M, Pan F. Common trace metals in rheumatoid arthritis: a systematic review and meta-analysis. J Trace Elem Med Biol 2019; 56:81-89.doi: 10.1016/ j.jtemb.2019.07.007.

4. Ali HM, Al-Zubaidi MA.Evaluation of trace elements in Iraqi patients with rheumatoid arthritis by using atomic absorption spectrophotometer (AAS). Iraqi J Pharm Sci 2012; 21(2): 77- 84.

5. Strecker D, Mierzecki A, Radomska K. Copper levels in patients with rheumatoid arthritis. Ann Agric Environ Med 2013; 20 (2): 312-6.

6. Ralston SH, McInnes IB. Rheumatology and bone disease. In: Walker BR, Colledge NR, Ralston SH, Penman ID, editors. Davidson's Principles and Practice of Medicine. Edinburgh: Elsevier;2014. p.1057- 1136 .

7. Khanna S, Jaiswal KS, Gupta B. Disease modifying antirheumatic diets: The new treatment modalities for rheumatoid arthritis. EMJ Rheumatol 2018; 5(1): 93-99.

8. Manole C, Mihaela CI, Lucia M, Isabela S, Minerva G. Changes of serum magnesium levels in patients with rheumatoid arthritis stage i-ii before treatment. Med Con 2011; 6(2): 9-12.

9. Ullah Z, Ullah MI, Hussain S, Kaul H, Lone KP. Determination of serum trace elements $(\mathrm{Zn}, \mathrm{Cu}$ and $\mathrm{Fe}$ ) in Pakistani patients with rheumatoid arthritis. Biol Trace Elem Res 2017; 175(1): 1016. doi: 10.1007/s12011-016-0746-8.

10. Onal S, Nazýroglu M, Colak M, Bulut V, FloresArce MF. Effects of different medical treatments on serum copper, selenium and zinc levels in patients with rheumatoid arthritis. Biol Trace Elem
Res 2011; 142(3):447-455. doi:10.1007/s12011010-8826-7.

11. Afridi HI, Kazi TG, Kazi N, Shah AQ, Khan S, Kolachi NF, Wadhwa SK, Shah F. Evaluation of calcium, magnesium, potassium and sodium in biological samples (scalp hair, serum, blood and urine) of Pakistani referents and arthritis patients of different age groups. Clin Lab 2012; 58 (1-2):718 .

12. Sahebari M, Ayati R, Mirzaei H, Sahebkar A, Hejazi S, Saghafi M, Saadati N, Ferns GA, GhayourMobarhan M. Serum trace element concentrations inrheumatoid arthritis. Biol Trace Elem Res 2016; 171: 237-245. doi: 10.1007/s12011-015-0501-6.

13. Saptarini NM, Wibowo MS, Gusdinar T. Correlation study of serum calcium levels and serum cartilage oligomeric matrix protein levels in rheumatoid arthritis patients in Bandung, Indonesia. Asian J Pharm Clin Res 2017; 10(11):401403.doi:10.22159/ajpcr.2017.v10i11.18493.

14. Masoud S, Lim PB, Kitas GD, Panoulas V. Sudden cardiac death in patients with rheumatoid arthritis. World J Cardiol 2017; 9(7):562-573. doi: 10.4330/ wjc.v9.i7.562.

15. Lazzerini PE, Capecchi PL, Laghi-Pasini F. Systemic inflammation and arrhythmic risk: lessons from rheumatoid arthritis. Eur Heart J 2017; 38: 1717-1727.doi:10.1093/eurheartj/ehw208.

16. Saminathan MB, Sharma R, Gogna A, Rani A, Kapoor R. Correlation of inflammatory markers and disease severity with cardiovascular autonomic dysfunction in Indian patients with rheumatoid arthritis. Indian J Rheumatol 2019; 14:1236.doi:10.4103/injr.injr_171_18.

17. Task force of the European Society of Cardiology and the North American Society of pacing and electro physiology. Heart rate variability. Standards of measurement, physiological interpretation and clinical use. Eur Heart J 1996; 17: 354-381.

18. Shaffer F, McCraty R, Zerr CL. A healthy heart is not a metronome: an integrative review of the heart's anatomy and heart rate variability. Front psycho 2014;5:1040.doi: 10.3389/fpsyg.2014. 01040

19. Adlan AM, Lip GYH, Paton JFR, Kitas GD, Fisher JP. Autonomic function and rheumatoid arthritisa systematic review. Semin Arthritis Rheum 2014; 44(3): 283-304.doi:10.1016/j.semarthrit.2014. 06.003 .

Volume 16 No. 2 December 2021: 111-117 
20. Ahamed S, Sheriff R. Analysis of heart rate variability in patients with chronic rheumatoid arthritis. Int J Clin Exp Physiol 2016; 3: 204-8. doi:10.4103/2348-8832.196914.

21. Chavan VU, Ramavataram DVSS, Patel PA, Rupani MP. Evaluation of serum magnesium, lipid profile and various biochemical parameters as risk factors of cardiovascular diseases in patients with rheumatoid arthritis. J Clin Diagnos Res 2015; 9(4): 1-5.doi: $10.7860 / \mathrm{JCDR} / 2015 / 12206.5740$.

22. Moustafa SR, Al-Taweel N, Mohsen F. Association of Boron, Copper, Germanium, Magnesium, Selenium and Zinc with incidence of rheumatoid arthritis. Am J Intern Med 2015; 3(3):132-140. doi: $10.11648 /$ j.ajim.20150303.17.

23. Kim YH, Jung KI, Song CH. Effect of serum calcium and magnesium on heart rate variability in adult women. Biol Trace Elem Res 2012;150:116-122.

24. Matei D, Luca C, Andritoi D, Sardaru D, Corciova C. The relationship between lower serum magnesium levels and heart rate variability indices.
Balneo Res J 2018; 9(4): 426-432.doi:10.12680/ balneo.2018.226.

25. Mohan P, Udayakumar KP, Hiramath PB. Does the frequency domain parameters among pregnant women with gestational hypertension associated with levels of serum zinc, magnesium and copper? A cross sectional study. Natl J Physiol Pharm Pharmacol 2020; 10 (9): 1-5. doi: 10.5455/ njppp.2020.10.04099020201062020.

26. Rensburg DCJV, Ker JA, Grant CC, Fletcher L. Autonomic impairment in rheumatoid arthritis. Int J Rheum Dis 2012; 15(4):419-426.

27. Yadav RK, Gupta R, Deepak KK. A pilot study on short term heart rate variability and its correlation with disease activity in Indian patients with rheumatoid arthritis. Indian J Med Res 2012; 136(4):593 8 .

28. Adlan AM, van Zanten JJCSV, Lip GYH, Paton JFR, Kitas GD, Fisher JP. Cardiovascular autonomic regulation, inflammation and pain in rheumatoid arthritis. Auton Neurosci 2017; 208 :137-145. doi:10.1016/j.autneu.2017.09.003. 